\title{
Rural-to-urban migration and its implication for new cooperative medical scheme coverage and utilization in China
}

Peiyuan Qiư ${ }^{\dagger}$, Yang Yang ${ }^{\dagger}$, Juying Zhang and Xiao $\mathrm{Ma}^{*}$

\begin{abstract}
Background: China has been experiencing the largest rural to urban migration in history. Rural-to-urban migrants are those who leave their hometown for another place in order to work or live without changing their hukou status, which is a household registration system in China, categorizing people as either rural residents or urban residents. Rural-to-urban migrants typically find better job opportunities in destination cities, and these pay higher salaries than available in their home regions. This has served to improve the enrollment rates in the New Cooperative Medical Scheme (NCMS) of rural families, protecting households from falling into poverty due to diseases. However, current regulations stipulate that people who are registered in China's rural hukou can only participate in their local NCMS, which in turn poses barriers when migrants seek medical services in the health facilities of their destination cities. To examine this issue in greater depth, this study examined the associations between migration, economic status of rural households, and NCMS enrollment rate, as well as NCMS utilization of rural-to-urban migrants.
\end{abstract}

Methods: A multistage cluster sampling procedure was adopted. Our sample included 9,097 households and 36,720 individuals. Chi-square test and T-test were used to examine differences between the two populations of migrants and non-migrants based on age, gender, marriage status, and highest level of education. Ordinal logistic regression was used to examine the association between migration and household economic status. Binary logistic regression was used to examine the associations between household economic status, migration and enrollment in the NCMS.

Results: Migration was positively associated with improved household economic status. In households with no migrants, only $11.3 \%$ of the population was in the richest quintile, whereas the percentage was more than doubled in households with family members who migrated in 2006. Among those using in-patient medical services, $54.3 \%$ of migrants in comparison with $17.5 \%$ of non-migrants used out-of-county hospitals, many of which were not designated hospitals (Designated hospitals refer to hospitals where, if people use in patient health care, could receive reimbursement from the NCMS.); and 55.2\% of migrants in comparison with $24.6 \%$ of non-migrants, who had the NCMS in 2006, received no reimbursement from the NCMS. The three main reasons of not receiving reimbursement were: staying in a hospital not designated by the NCMS, lack of knowledge of NCMS policies, and encountering difficulties obtaining reimbursement.

Conclusion: Migrants to urban centers improve the economic status of their rural household economic of origin. However, obtaining reimbursement under the current NCMS for the cost of hospital services provided by undesignated providers in urban centers is limited. Addressing this challenge is an emerging policy priority.

Keywords: rural-to-urban, migration, New Cooperative Medical Scheme, NCMS, China

\footnotetext{
* Correspondence: huaxihe2009@gmail.com

+ Contributed equally

West China School of Public Health, Sichuan University, No. 17, Section 3,

South Renmin Road, Chengdu, Sichuan, China
} 


\section{Background}

Medical debt can prevent rural households from moving out of poverty or can drive families into poverty [1]. In China, the central government has been striving to create universal medical insurance. Currently, the country has three primary health insurance programs, namely, the Urban Employee Basic Medical Insurance (UEBMI) for the urban employed, the Urban Resident Basic Medical Insurance (URBMI) for urban residents, and the New Cooperative Medical Scheme (NCMS) for rural residents. The NCMS was initiated in rural China in 2003, which is a scheme of voluntary mutual assistance among participating rural residents improving access to health care services and protecting against catastrophic illnesses [2,3]. The NCMS is financed in China's poorer central and western regions by a combination of contributions from the central government, local governments, and individuals. In 2006, at the time of our sampling, annual contributions amounted to RMB20 (Chinese yuan) per insured person from the central government, RMB15-20 from the local governments, and RMB10-15 from each insured individual [4]. (By 2010, these had increased to RMB60, RMB60, and RMB30, respectively, and the premium paid by rural residents in households identified as "poor" (about 5\% of total households) has been waived $[5,6]$.) The unit of enrollment is at household level in order to avoid adverse selection within the household [7]. National guidelines of the NCMS focus on the coverage of in-patient care, while some provinces have been in fact developing a benefit package covering both outpatient and inpatient services. Reimbursement rates differ, with higher rates (35\%-60\%) at rural township health care centers and lower rates (25\%-40\%) at county-level facilities. Because funding for the NCMS is determined at the county level, it commonly requires participants to use designated facilities within the county, which often are county-level hospitals and township health care centers. Of note, and particularly important for this study, while NCMS plans pay for services provided outside of the home counties [8], the reimbursement rates are discounted sharply (10\%-25\%). According to NCMS regulations, the ceiling level of reimbursement in 2006 was RMB10,000-20,000 per participant per year. (This was increased to RMB50,000-100,000 per participant per year by 2010.)

Previous research mainly focused on impact evaluation on the NCMS, willingness to join the NCMS, equality of the NCMS, and adverse selection in the NCMS [7,9-13]. Nevertheless, little empirical research has been done on the associations between rural-to-urban migration and NCMS coverage and utilization in rural China. Rural-tourban migrants are those who leave their hometown for another place in order to work or live without changing their hukou status. Hukou is a household registration system in China [14], categorizing people as either rural residents or urban residents. When strictly enforced in past times, one's hukou defined where an individual could live and work [14,15]; even now it affords different rights to migrants and local residents. For decades, hukou has functioned like an "internal passport system" [16]. A study among rural-to-urban migrants in Indonesia found that migrants were more likely to have insurance coverage, because health insurance in Indonesia was made available primarily through urban employers, which resulted in a higher utilization of medical care among migrants [17]. China, with a large population of internal rural-to-urban migrants, has a different story.

Since the mid-1980s, migration in China has been economically driven. Residents from less developed rural regions in western and central China traveled to developed cities and eastern industrial zones ("urban centers") to seek better job opportunities and higher incomes. They typically send remittances to their families, providing financial support, while returning to their homes for holidays and occasionally for helping with the harvest. Based on data from National Bureau of Statistics of China, $10.0 \%$ of migrant workers sent $30 \%-40 \%$ of their income to their families; $15.3 \%$ sent $40 \%-50 \%$ of earnings; $11.2 \%$ sent $50 \%-60 \%$; $23.5 \%$ sent $60 \%-70 \%$; and $9.2 \%$ sent $70 \%-80 \%$ of their income home [18].

These rural-to-urban migrant workers have made a tremendous contribution to China's economic development and played an important role in financial safety of their families. The NCMS is designed exclusively for rural people, according to their hukou. Funding of the NCMS is based on the county level of governmental organization; therefore, it is expected that people will seek medical services in designated hospitals, most of which are located within the home county. Nevertheless, this is impractical for migrant workers, limiting how much they can use their NCMS benefits. At the same time, this population faces a dilemma in terms of access to health insurance in cities. Rural-to-urban migrants always are excluded from city health systems, so that most of them cannot qualify for the UEBMI and URBMI, as if they were local city residents, even when they are working in the same company and living in the same community [19]. But as they are out-of-county, reimbursement for city services is severely limited.

In this study we examined the associations between migration and household economic status, enrollment in the NCMS, and use of its benefits. Specifically, we anticipated that migration had a positive association with household economic status, which may in turn improve the enrollment rate in the NCMS of families 
potentially. However, since people who hold rural hukou are expected to participate in and get reimbursement from the NCMS in the location of their hukou, migrants in urban centers confront difficulty when seeking medical services in the health facilities of their destination cities [2].

In turn, this lack of meaningful "insurance portability" eventually may lead to a lower long-term enrollment in the NCMS by premium-paying migrants, thus jeopardizing the viability of the system in the future. To date, we know of no related empirical research regarding these issues, although some authors have discussed challenges, such as a low reimbursement rate associated with the NCMS for migrants [20].

\section{Methods}

\section{Key concepts}

A migrant in the study is defined as an individual who moved in 2006 from the place of his/her rural hukou to another place in order to work or live without a change in hukou. A minimum of six months in residence away from home was required to qualify.

We defined persons suffering major illness as those who either accepted hospital treatment at least once or spent a minimum of RMB1000 on outpatient services, or experienced a diagnosed disability in 2006.

\section{Sources of data}

A household survey was undertaken in two purposively selected counties in Sichuan Province in the Southwestern China and another two in Hubei Province in Central China as part of the program "Protecting the rural poor against the economic consequences of major illness: A challenge for Asian transitional economies (POVILL)". With a large number of rural residents, Sichuan and Hubei are two of the underdeveloped provinces in China and also major provinces to export labor. Inclusion criteria for counties included being a NCMS pilot county (except for the control county), and being a national-level poor county. In each area, a multistage cluster sampling procedure was adopted to select village communities, each consisting of around 100 households. All households in these communities were enumerated, giving a total sample of around 12,000 households. In this study, we recruited three of the four counties that had implemented the NCMS in 2006, yielding a sample of 9,097 households and 36,720 individuals (Table 1). Professors and graduate students from West China School of Public Health, Sichuan University and from Zhongnan University of Economics and Law were trained to conduct household surveys.

\section{Data collection}

A questionnaire developed for this study was used to interview the target population. The questionnaire has five sections. Sections A and E were used to collect household data on economic status, enrollment status in the NCMS, and utilization of the NCMS. Sections B, C and $\mathrm{D}$ were designed to obtain individual information on socio-demographic characteristics, health care demand and utilization by those who were sick in the past 14 days and health care demand and utilization by people who suffered major illness in 2006. Informed consent was obtained from all participants following a protocol that was approved by Ethics Committee of Sichuan University.

The household head or the person who knew family issues best was asked to answer all of the five sections and other family members were asked to finish Sections $\mathrm{B}, \mathrm{C}$ and D. For those who were not at home when the interview was conducted, family members helped to provide their information.

\section{Asset index construction}

Household income and expenditure are usually used as a tool for classifying household economic status. However, several investigators have noted potential limitations of this measure $[21,22]$. The quality of income and expenditure data may be questionable. These data are collected on the basis of personal recall and are prone to measurement errors. Problems of inaccurate reporting of income and expenditure, and difficulties in converting household products into monetary terms also serve as concerns.

Thus, an asset-based index was introduced and developed as an alternative tool for classifying household economic status [21-24]. Considering that rural people in China usually have household products, which are very difficult to monetize, we constructed an asset index by using principal component analysis

Table 1 Basic information of the three counties

\begin{tabular}{|c|c|c|c|}
\hline Indicators & Hongan, Hubei & Langzhong, Sichuan & Fushun, Sichuan \\
\hline Total population (N) & 650,000 & 860,000 & $102,000,0$ \\
\hline Rural population (N) & 540,000 & 600,000 & 830,000 \\
\hline Average annual income of rural population (RMB/capital year) & 2,328 & 2,889 & 3,400 \\
\hline Number of households involved in the study $(\mathrm{N})$ & 3,043 & 2,969 & 3,085 \\
\hline Number of individuals involved in the study $(\mathrm{N})$ & 12,712 & 11,079 & 12,929 \\
\hline
\end{tabular}


(PCA). Eleven variables from Section A of the questionnaire were used to calculate the PCA (Appendix A). The first principal component (eigenvalue: 3.315 , account for $30.14 \%$ ) was used to quintile the household economic status (Appendix B). As a result, each household was assigned into one of the five quintiles (Figure 1).

\section{Data analysis}

Sociodemographic characteristics of migrants and nonmigrants, including age, gender, highest education level, and marital status were described. Chi-square test and $\mathrm{T}$-test were used to examine differences between the two populations of migrants and non-migrants based on these characteristics.

Household economic status and NCMS enrollment rates in the households with different migration characteristics were described first. Ordinal logistic regression was used to examine the association between migration and household economic status. The dependent variable was the quintile economic status using $1=$ richest, $2=$ second, $3=$ middle, $4=$ fourth, and $5=$ poorest. Independent variables included household inactive labor force rate, household migration rate, household gender ratio, household head's education level, household disease burden, and household size.

(1) Household inactive labor force rate $=$ the number of people not working in a household/household size (2) Household migration rate $=$ the number of migrants in a household/household size

(3) Household gender ratio $=$ the number of males in a household/household size

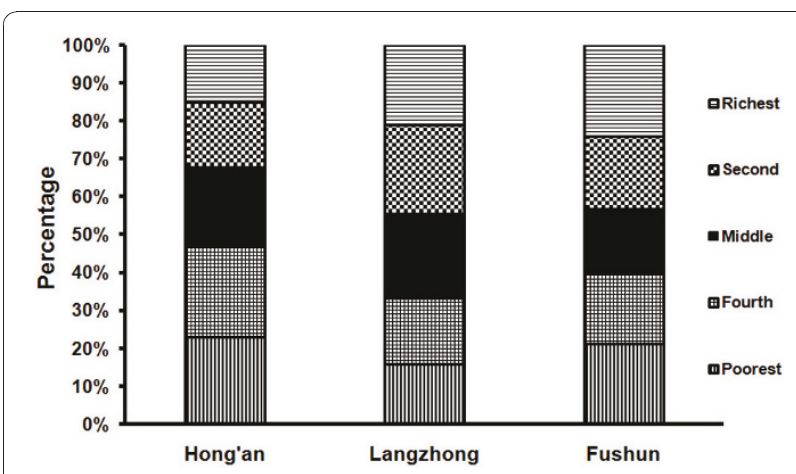

Figure 1 The distribution of household economic status by county. An asset index was constructed by using principal component analysis (PCA) to classify household economic status. Eleven variables from Section $A$ of the questionnaire were used to calculate the PCA (Appendix A). The first principal component (eigenvalue: 3.315 , account for $30.14 \%$ ) was used to quintile the household economic status (Appendix B). As a result, each household was assigned into one of the five quintiles.
(4) Household head's education level was defined as 1 = illiteracy, 2 = primary school, 3 = middle school, and $4=$ high school and above

(5) Household disease burden $=$ the number of people with a major illness/household size

(6) Household size $=$ the number of people who were under the same hukou

Binary logistic regression was used to examine the relationships between household economic status, migration and enrollment in the NCMS. The dependent variable was whether a household was participating in the NCMS in 2006, where $0=$ non-enrollment and 1 = enrollment. Independent variables included household economic status, household migration rate, household head's education level, household disease burden, and household size. Statistical significance was defined as $P \leq 0.05$.

In addition, reimbursement rates, type of health care institutions where to seek inpatient care, and reasons for not receiving NCMS reimbursement for non-migrants and migrants who had received inpatient services in 2006 were described.

\section{Results}

\section{Sample description}

The sample generated in our investigation consisted of a total of 9,097 households and 36,720 individuals. Because migration status was missing for 260 individuals, the sample for this analysis consisted of 9,018 households and 36,460 individuals. Table 2 presented the distributions of the study variables for the valid sample. In this sample: $34.3 \%$ of the population were migrants. Migrants were younger than non-migrants $(t=62.801, P<0.001)$. The mean age was 42.7 years for non-migrants and 28.9 years for migrants. The data indicated that much more males than females migrated (60\% vs. $\left.40 \%, \chi^{2}=441.876, \mathrm{df}=1, P<0.001\right)$. Marital distribution between non-migrants and migrants was different $\left(\chi^{2}=1346.186, \mathrm{df}=3, P<0.001\right)$, with $28.4 \%$ unmarried among non-migrants and $40.2 \%$ among migrants. Education level between non-migrants and migrants also differed significantly $\left(\chi^{2}=6735.647\right.$, $\mathrm{df}=5, P<0.001)$. Compared with non-migrants, more migrants had completed middle school or more education $(62.1 \%$ vs. $25.9 \%)$.

\section{Associations between migration, household economic status, and enrollment in the NCMS}

Table 3 showed that $11.3 \%$ of the population in households with no migrants was in the richest quintile; whereas the percentages were $23.9 \%$ and $23.2 \%$ for households with half or fewer and more than half of family members migrating in 2006, respectively. 
Table 2 Demographic characteristics of non-migrants and migrants

\begin{tabular}{|c|c|c|c|}
\hline & & Non-migrants & Migrants $^{\mathrm{a}}$ \\
\hline \multirow[t]{2}{*}{ Age (S.D) } & & $42.7(23.4)$ & $28.9(10.5)$ \\
\hline & & & $t=62.801, P<0.001$ \\
\hline \multirow[t]{3}{*}{ Gender (\%) } & Male & 48.4 & 60.0 \\
\hline & Female & 51.6 & 40.0 \\
\hline & & & $\chi^{2}=441.876, \mathrm{df}=1, P<0.001$ \\
\hline \multirow[t]{5}{*}{ Marriage Status (\%) } & Unmarried & 28.4 & 40.2 \\
\hline & Married & 62.9 & 58.4 \\
\hline & Divorced & 0.3 & 0.9 \\
\hline & Widowed & 8.4 & 0.5 \\
\hline & & & $\chi^{2}=1346.186, \mathrm{df}=3, P<0.001$ \\
\hline \multirow[t]{6}{*}{ Highest level of education (\%) } & Illiteracy & 36.7 & 3.2 \\
\hline & Primary school & 37.4 & 29.8 \\
\hline & Middle school & 20.5 & 49.2 \\
\hline & High school & 5.1 & 12.9 \\
\hline & College and above & 0.3 & 4.9 \\
\hline & & & $\chi^{2}=6735.647, \mathrm{df}=5, P<0.001$ \\
\hline
\end{tabular}

a. Migrant here is defined as an individual who move from the place where his/her hukou is to another place for at least six months in order to work or live in 2006.

Meanwhile, in households with no migrants, $34.3 \%$ of the population was classified into the poorest quintile, compared with $13.6 \%$ and $15.0 \%$ in households with half or fewer and more than half of family members migrating in 2006, respectively. Households with half or fewer members migrating in 2006 had an enrollment rate of $90.4 \%$, and households with more than half of its members as migrants had an enrollment rate of $86.9 \%$. Enrollment rates of richest, second, middle, fourth and poorest quintiles were $92.0 \%, 91.6 \%, 90.7 \%, 89.2 \%$, and $83.9 \%$, respectively. The poorest had the lowest enrollment rate.

The ordinal logistic regression model (Table 4) showed that factors positively associated with household's economic status were lower inactive labor force rate, higher household migration rate, higher education level of household head, lower household disease burden and larger household size. Analysis of the results indicated that after controlling for household size, inactive labor force rate, household head's education level, household disease burden, and household gender ratio, migration still had a positive association with household economic status.

In the binary logistic regression model (Table 5), a household was more likely to enroll in the NCMS if household economic status was higher, household migration rate was lower and household size was larger. Relationships between enrollment rate and household head's education level, as well as gender ratio of a

Table 3 Household economic status and enrollment in the NCMS of households with different migration characteristics

\begin{tabular}{|c|c|c|c|c|c|}
\hline & & \multicolumn{3}{|c|}{ Households with different migration characteristics } & \multirow[b]{2}{*}{ Total (\%) } \\
\hline & & $\begin{array}{l}\text { Households with } \\
\text { no migrants (\%) }\end{array}$ & $\begin{array}{l}\text { Households with half or fewer family } \\
\text { members migrating in } 2006(\%)\end{array}$ & $\begin{array}{l}\text { Households with more than half of } \\
\text { family members migrating in } 2006(\%)\end{array}$ & \\
\hline \multirow{6}{*}{$\begin{array}{l}\text { Household } \\
\text { economic } \\
\text { status }\end{array}$} & Richest & 11.3 & 23.9 & 23.2 & 20.0 \\
\hline & Second & 14.7 & 22.6 & 20.7 & 20.0 \\
\hline & Middle & 17.7 & 20.3 & 23.6 & 20.0 \\
\hline & Fourth & 21.9 & 19.6 & 17.5 & 20.0 \\
\hline & Poorest & 34.3 & 13.6 & 15.0 & 20.0 \\
\hline & Total & 100.0 & 100.0 & 100.0 & 100.0 \\
\hline \multirow{3}{*}{$\begin{array}{l}\text { Did you join } \\
\text { the NCMS? }\end{array}$} & Yes & 89.2 & 90.4 & 86.9 & 89.5 \\
\hline & No & 10.8 & 9.6 & 13.1 & 10.5 \\
\hline & Total & 100.0 & 100.0 & 100.0 & 100.0 \\
\hline
\end{tabular}


Table 4 Results of ordinal logistic regression on household economic status

\begin{tabular}{|c|c|c|}
\hline & $\begin{array}{l}\text { Household economic status } \\
(1=\text { richest, } 2=\text { second, } \\
3=\text { middle, } 4=\text { fourth, and } \\
5=\text { poorest })\end{array}$ & \\
\hline & OR $(95 \% \mathrm{Cl})$ & $P$ \\
\hline $\begin{array}{l}\text { Household } \\
\text { unemployment rate }\end{array}$ & $2.334(1.999,2.723)$ & $<0.001$ \\
\hline $\begin{array}{l}\text { Household migration } \\
\text { rate }\end{array}$ & $0.687(0.582,0.813)$ & $<0.001$ \\
\hline $\begin{array}{l}\text { Household head's } \\
\text { education level }\end{array}$ & $0.925(0.876,0.977)$ & 0.005 \\
\hline Household gender ratio & $1.201(0.962,1.499)$ & 0.105 \\
\hline $\begin{array}{l}\text { Household disease } \\
\text { burden }\end{array}$ & $1.617(1.450,1.804)$ & $<0.001$ \\
\hline Household size & $0.721(0.701,0.741)$ & $<0.001$ \\
\hline
\end{tabular}

household were not significant. The results indicated that increased household economic status may improve enrollment rate of the NCMS, but higher household migration rate may decrease enrollment rate.

\section{Access to hospital care and reimbursement of service expenses by non-migrants and migrants}

Out of those using in-patient services, $54.3 \%$ of migrants in comparison with $17.5 \%$ of non-migrants used out-ofcounty hospitals, many of which were not designated hospitals; and $55.2 \%$ of migrants in comparison with $24.6 \%$ of non-migrants, who had the NCMS in 2006, received no reimbursement from the NCMS and non-migrants received higher NCMS reimbursement rates than migrants $(Z=-9.239, P<0.001)$ (Table 6). Average reimbursement rates of local township health care centers, local county level hospitals, and out-of-town hospitals were 23.6\%, $15.7 \%$, and $4.4 \%$, respectively. Three primary reasons accounted for lower reimbursement rates, although they contributed differently to the difficulties encountered by

Table 5 Results of binary logistic regression on enrollment in the NCMS

\begin{tabular}{|c|c|c|}
\hline & \multicolumn{2}{|c|}{$\begin{array}{l}\text { Enrollment of the NCMS }(0=\text { non- } \\
\text { enrollment and } 1=\text { enrollment) }\end{array}$} \\
\hline & OR $(95 \% \mathrm{Cl})$ & $P$ \\
\hline $\begin{array}{l}\text { Household } \\
\text { migration rate }\end{array}$ & $0.402(0.298,0.543)$ & $<0.001$ \\
\hline $\begin{array}{l}\text { Household head's } \\
\text { education level }\end{array}$ & $0.938(0.845,1.041)$ & 0.225 \\
\hline $\begin{array}{l}\text { Household disease } \\
\text { burden }\end{array}$ & $1.120(0.926,1.355)$ & 0.242 \\
\hline $\begin{array}{l}\text { Household } \\
\text { economic status }\end{array}$ & $0.828(0.786,0.873)$ & $<0.001$ \\
\hline Household size & $1.139(1.081,1.200)$ & $<0.001$ \\
\hline
\end{tabular}

non-migrants and migrants: 1) Staying in a hospital that is not designated by the NCMS: non-migrants, $33.6 \%$; migrants, $64.9 \%$; 2) lack of knowledge of NCMS policies: non-migrants, $27.3 \%$; migrants, $12.2 \%$; and 3 ) encountering difficulties obtaining reimbursement: non-migrants, $18.6 \%$; migrants, $12.8 \%$.

\section{Discussion}

Rural-to-urban migration and NCMS coverage and utilization in China

Sichuan Province and Hubei Province are two of the largest sources of rural-to-urban migrants. In this study, $34.3 \%$ of the population were migrants. As showed in Table 2, migrants, as compared with non-migrants, tend to be younger men having higher education level. Because they are younger, the unmarried proportion is larger. The results are in accordance with previous studies $[25,26]$.

While internal rural-to-urban migration during the past two decades has fueled China's economic transformation, in particular supplying an essential workforce for its export economy and the growth of its cities, it also has served as a key element in improving the economic circumstances of rural regions. People migrate to cities for better job opportunities and higher incomes, and to assist their families economically. Though many migrants only return home for the Traditional Spring Festival, their remittances may be the primary source of household income, providing an important financial safety net against the risks of crop failure, ill health, or other shocks to rural households (e.g., weather related). The National Bureau of Statistics of China reported that, $43.8 \%$ of migrant workers sent more than $50 \%$ of their income back home in 2006 [21].

In a related vein, Tan found among rural households from 1985 to 2007, the proportion of salaried income, as a component of the total household earnings, increased from $18.0 \%$ to $38.6 \%$ [27], underscoring the diminishing relative role of agrarian-generated income. Our study found that $34.3 \%$ of households without migrants were included in the poorest quintile. For households where half or fewer members were migrants, this dropped to $23.9 \%$, and for those with more than half as migrants, $23.2 \%$ were in the poorest quartile. Although we detected a positive association between migration and household economic status, we also recognize the potential limitation of our cross-sectional design, where it was not possible to determine premigration household economic status.

Household economic status was found to be positively associated with enrollment rate in the NCMS; however, we detected that, while rural households in general have a higher enrollment in the NCMS, the enrollment rate 
Table 6 Use of hospital care by type, NCMS reimbursement rate, and reasons of not receiving NCMS reimbursement by non-migrants and migrants receiving inpatient services in 2006

\begin{tabular}{|c|c|c|c|}
\hline & & $\begin{array}{c}\text { Non- } \\
\text { migrants }\end{array}$ & Migrants \\
\hline & & $\%$ & $\%$ \\
\hline \multirow[t]{4}{*}{ Use of hospital care by type } & Local township health care centers & 39.0 & 17.8 \\
\hline & Local county level hospitals & 43.5 & 27.9 \\
\hline & $\begin{array}{l}\text { Out-of-county hospitals (city level and above hospitals, } \\
\text { private hospitals) }\end{array}$ & 17.5 & 54.3 \\
\hline & Total & 100.0 & 100.0 \\
\hline \multirow[t]{7}{*}{ NCMS reimbursement rates ${ }^{a}$} & $0 \%$ & 24.6 & 55.2 \\
\hline & $>0 \%$ and $\leq 10 \%$ & 16.0 & 9.3 \\
\hline & $>10 \%$ and $\leq 20 \%$ & 18.1 & 16.0 \\
\hline & $>20 \%$ and $\leq 30 \%$ & 19.2 & 8.6 \\
\hline & $>30 \%$ and $\leq 40 \%$ & 15.0 & 7.1 \\
\hline & $>40 \%$ & 7.0 & 3.7 \\
\hline & Total & 100.0 & 100.0 \\
\hline \multirow{7}{*}{$\begin{array}{l}\text { Reasons of not receiving NCMS reimbursement after } \\
\text { inpatient services }^{a}\end{array}$} & Deductible fee is higher than inpatient services expenditure & 8.6 & 4.1 \\
\hline & Most of the expenses could not be covered by the NCMS & 9.5 & 2.7 \\
\hline & Stay in a hospital that is not designated by the NCMS & 33.6 & 64.9 \\
\hline & Lack of knowledge of the NCMS policies & 27.3 & 12.2 \\
\hline & Encountering difficulties obtaining reimbursement & 18.6 & 12.8 \\
\hline & Others $^{b}$ & 2.3 & 3.4 \\
\hline & Total & 100.0 & 100.0 \\
\hline
\end{tabular}

a. Only people who had the NCMS in 2006 were included in the analysis.

b. Others include other people paying for the inpatient expenses, and other insurance paying for inpatient expenses

in 2006 was slightly lower for those where more than half of the family members worked as migrants. Competing forces may be influencing these findings: 1) The participation unit is a household rather than an individual, which tends to avoid the effect of adverse selection [13], especially as migrants themselves tend to be younger and in good health; 2) migration may improve household economic status, relieving the burden of NCMS premium and promoting a higher enrollment rate; 3 ) given the very limited benefits eligibility of migrants working in cities far from their hukou, household having many migrant members may choose not to participate in the NCMS in the future.

In fact, our data revealed that seeking hospital care in out-of-county hospitals resulted in a much lower reimbursement rates or even no reimbursement from the NCMS. However, $54.3 \%$ of migrants chose hospital care in out-of-town hospitals, usually where they worked and lived. As a result, a high proportion of migrants (55.2\%) who used inpatient services in 2006 received no NCMS reimbursement from for these services.

National policy has long been established on localitybased schemes that depend on hukou as an organizing principle: Like many initiatives, the NCMS continues to be financed and administered by county governments, and understandably requires local enrollees to use designated facilities within the county. This is likely to be exacerbated by the greater costs of urban (better equipped and better staffed) medical centers in comparison to the costs associated with China's modest town hospitals. Even for the few NCMS plans that accept medical bills from urban hospitals [8], the level of payment is extremely low and the procedures for reimbursement to individuals often are long, cumbersome, and unpleasant. In one of our study sites, Hong'an County, NCMS plan reimburses participants for $50 \%$ of the inpatient services cost in a township health care center, 35\%$50 \%$ of that in a county hospital, and $12.5-20 \%$ in a hospital out of the home county (2006 rates). When migrants do receive out-of-county services, they must inform their hometown health department before service delivery, as well as provide proof of employment in the city. The other two counties included in our study have similar procedures.

An additional system-level challenge may relate to the newness of the NCMS insurance scheme. According to the "Funding Regulation on the New Cooperative Medical Scheme" published by the Ministry of Finance and Ministry of Health [28], surplus funds at the end of the year should not exceed $15 \%$ of revenue, and the cumulative surplus should be remain less than $25 \%$. During the initial phases of implementation, many 
NCMS management teams were concerned about exhausting annual revenues and worked vigorously to build reserves. A case study on the financial management of the NCMS in six counties in two Chinese provinces found that five out of six held a large fund surplus, while their enrollees obtained only partial financial protection [29]. In order to reduce schemes surpluses, some counties will do a second round reimbursement usually at the end of a year. In our sample counties, the surplus proportions were $24 \%$ in Hong'an County and 30\% in Langzhong and Fushun County, even after the second round reimbursement in 2006, indicative of implementation policies that may discourage making appropriate payments for needed out-ofcounty care.

We observed two other important reasons for insufficient payments. Some participants reported that they did not know how to obtain reimbursement, and some old people living alone in the countryside did not know how to use the NCMS. The NCMS was started in Fushun in 2005 and in Langzhong and Hong'an in 2006. Changes are said to be forthcoming, and in the near future, patients will not need to pay the full cost in advance, but their copayment [30].

\section{Policy implication}

China is experiencing the largest in-country rural-tourban migration in history. Data from National Bureau of Statistics of China in 2009 showed that China had 145 million rural-to-urban migrants, and the number has been increasing yearly [31]. Young and healthy people leave their hometown for better job opportunities and higher income in urban and industrial centers, leaving elders and children at home. Migration may contribute to improving household finances, which in turn will improve the ability to join the NCMS. However, the policy is not fair to migrants. Although current NCMS policy requires the enrollment unit to be a household, tending to avoid adverse selection in the near term, continuing barriers to "portability" likely will lead to a decline in enrollment in the longer term as greater numbers continue to leave rural counties across China.

Migrant workers work and live in the city, making it difficult for them to go back to seek medical care, which results in a low utilization of the NCMS. Theoretically, the NCMS should extend its benefits to migrants. In reality, however, the opportunities to sustainably increase the financial protection offered to NCMS enrollees are limited by the financial pressures on local governments [29]. Poor rural counties have very limited resources to support coverage of health care in expensive urban hospitals. This raises a question of whether the cities where migrants move to work should contribute towards insuring against medical costs.
Even though the Urban Employee Basic Medical Insurance in some cities will cover students whose parent(s) legally work in the city, it seldom covers migrant workers themselves [32]. In some cities, such as Guangzhou and Chengdu, local governments are developing projects to recruit rural-to-urban migrant workers into the Urban Employee Basic Medical Insurance. While this approach may hold promise, it may have the unintended consequence of further undermining the financial structure of the NCMS by withdrawing the contributions from economically and healthily better-off migrants from the rural contribution pool. Chengdu, the capital of Sichuan Province, is also piloting an approach that seeks to integrate health insurance for rural and urban residents. This collaborative method, with possible regional applicability, may not be easily generalized in light of the diverse management and benefit plans across the country. In addition, not all provinces have an economically robust 'anchor city' such as Chengdu. Our results underscore the need for further study and careful planning regarding how to best assure adequate health insurance for migrant workers, and ultimately, universal coverage for the entire country. No doubt, this will be a formidable challenge.

\section{Limitations}

We are very much aware that this was a cross-sectional study, and it cannot be used to attribute causal relations. To understand the impact of rural-to-urban migration on household economic status, and on NCMS coverage and utilization, longitudinal research designs will be needed. Other variables, such as type of disease and seriousness of disease, are important factors for household economic status and NCMS utilization. However, we did not have enough information to evaluate their influence, which may result in underestimate mis-estimation of the associations.

\section{Conclusion}

This study featured several noteworthy elements. It showed both a high enrollment rate in the NCMS and a low reimbursement rate for those who received inpatient services, especially among migrants. This low level of support from the NCMS-in practice, failing to increase the financial protection of rural-to-urban migrants-may negatively influence future participation of households with migrants. In some cities, local government has initiated pilot projects integrating health insurance systems integration, but the benefits of this kind of integration will be very limited in a short term due to small scale and the diverse management systems across the country.

In sum, the future of China's dynamic migrant worker economy will depend, in part, on the future of health 
insurance plans. Portability is one critical feature. Moreover, "health security" likely will be an essential element when fostering worker security and retention. As China continues its evolution toward a more highly trained workforce, one with ever-greater technical sophistication, there will be increasing attention to "human capital", and the adequacy of health insurance will serve as a key foundation stone.

\section{Appendices Appendix A}

We exploited a range of 11 variables of household assets (Clock/watch, television, phone/mobile, electric fan, VCD/DVD, sofa, furniture, walls made of grass, clay or adobe, floor made of clay, age of house, and floors of the house), which could be classified into two groups: housing characteristics, and ownership of household durable and semi-durable assets. Most variables were dichotomous having a value of either zero or one. Variables that were not dichotomous such as materials used in housing construction were changed into a dichotomous character, permanent or non-permanent materials of housing construction.

\section{Appendix B}

A common method to extract principal components is to select components where the associated eigenvalue is greater than one. However, it is assumed that the first principal component is a measure of economic status [33]. McKenzie [34] considered the use of additional principal components in characterizing household economic status and concluded that only the first principal component was necessary for measuring wealth. In addition, Filmer and Pritchett pointed out that the factor scores for each variable were difficult to interpret if considering the use of additional components [22]. In previous studies, the first principal component accounted for a range from $12 \%$ to $27 \%$ of total variation, and in our study, the first principal component accounted for $30.14 \%$. The percentage is not high, which may reflect the complexity of correlations between variables, as each included variable may have its own determinant other than SES [35].

\footnotetext{
Acknowledgements

This publication is an output of the POVILL Project, supported by the Sixth Framework Programme of the European Commission. Data analysis and paper publication were supported by CMB project (\#09-983) "the Evidencebased Research Center of West China Health". The authors would like to thank Dr. Bruno Meessen and Dr. Kristof Decoster from Institute of Tropical Medicine, Belgium for their expert assistance in project design, implementation, and data analysis, Professor Shijun Ding from Zhongnan University of Economics and Law for his great efforts in data collection, Professor Ellen Judd from the University of Manitoba for her helpful comments on an earlier version of this paper, and Eric D. Caine, M.D. from the University of Rochester, Alesa Sutherland from the University of
}

Manitoba, and Professor Dongtao Lin from Sichuan University for their assistance in preparing the manuscript.

\section{Authors' contributions}

$P Q$ and $Y Y$ participated in conduct of the study, data analysis and manuscript drafting. JZ participated in the project design, co-ordination and conduct of the study. XM was the principal investigator of the package 3 and package 4 of the project in China, and participated in the protocol development, project design, conduct of the study, and revision of drafts of the manuscript.

All authors read and approved the final manuscript.

\section{Competing interests}

The authors declare that they have no competing interests.

Received: 28 January 2011 Accepted: 30 June 2011

Published: 30 June 2011

\section{References}

1. Gustafsson B, Li S: Expenditures on Education and Health Care and Poverty in Rural China. China Economic Review 2003, 15:292-301.

2. You Xuedan, Kobayashi Yasuki: The New Cooperative Medical Scheme in China. Health Policy 2009, 91:1-9.

3. Center for China Cooperative Medical Scheme (CCMS): About CCMS: Backgroud (in Chinese) 2005.

4. Lei Xiaoyan, Lin Wangchuan: The New Cooperative Medical Scheme in Rural China: Does More Coverage Mean More Service and Better Health? Health Econ 2009, 18:S25-S46.

5. Liu Y, Rao K: Providing Health Insurance in Rural China: From Research to Policy. Journal of Health Politics, Policy and Law 2006, 31:71-91.

6. Watts J: China's Rural Health Reforms Tackle Entrenched Inequalities. The Lancet 2006, 367:1564-1565.

7. Zhang Licheng, Wang Hong: Dynamic Process of Adverse Selection: Evidence from a Subsidized Community-based Health Insurance in Rural China. Social Science \& Medicine 2008, 67:1173-1182.

8. Guo J, Liu X, Zhu X: Migrant Workers Are not Covered by NCMS (in Chinese). Outlook Weekly 2007, 47(2):S12.

9. Wang Hongman, Gu Dannan, Dupre Matthew Egan: Factors Associated with Enrollment, Satisfaction, and Sustainability of the New Cooperative Medical Scheme Program in Six Study Areas in Rural Beijing. Health Policy 2008, 85:32-44.

10. Wang Hong, Zhang Licheng, Yip Winnie, et al: Adverse Selection in a Volunrary Rural Mutual Health Care Health Insurance Scheme in China. Social Science \& Medicine 2006, 63:1236-1245

11. Zhaokang Yuan, Jiangang Zheng, Meijuan Zhang: A Five-year-follow-up Survey on the Effect of the New Rural Cooperative Medical System on Farmers' Medical Service Requirment and Utilization (in Chinese). Chinese Rural Health Service Administration 2008, 28:94-97.

12. Fei Zhang, Hui Wu, Dongxia Zhang, et al: Study about the Impact of New Cooperative Medical Scheme on the Participation's Hospital Cost (in Chinese). Chinese Health Economics 2008, 27:57-60.

13. Yu BR, Meng QY, Collins C, et al: How does the New Cooperative Medical Scheme influence health service utilization? A study in two provinces in rural China. BMC Health Services Research 2010, 10:116.

14. Roberts DKenneth: China's "Tidal Wave" of Migrant Labor: What Can We Learn From Mexican Undocumented Migration to the United States? The International Migration Review 1997, 31(2):249-291.

15. Chan KW: "Post-Mao China: a two-class urban society in the making". Int J Urban Reg Res 1996, 20:134-150.

16. Solinger D: "The floating population in the cities: chances for assimilation?". In Urban Spaces in Contemporary China: the Potential for Autonomy and Community in Post-Mao China. Edited by: Davis D, Kraus R, Naughton B, Perry F. New York: Cambridge University Press; 1995:113-139.

17. Lu Y: Rural-urban migration and health: Evidence from longitudinal data in Indonesia. Social Science \& Medicine 2010, 70:412-419.

18. National Bureau of Statistics of China: Investigation on Quality of Life of Migrant Workers: Living and Education (in Chinese) 2006

19. Dong $X$, Bowles P: "Segmentation and Dicrimination in China's Emerging Industrial Llabour Market". China Economic Review 2002, 13(2-3):170-196.

20. Guihua Luo, et al: Rural Population Floating Influence on Cooperative Medical System (in Chinese). Medicine and Society 2006, 9:4-6. 
21. Carletto C, et al: Validity of rapid estimates of household wealth and income for health surveys in rural Africa. Journal of Epidemiology and Community Health 2000, 54:381-387.

22. Pritchett $L$ : Estimating Wealth Effectes without Expenditure Data-or Tears: An Application of Educational Enrollment in States of India. Demography 2001, 38(1):115-132.

23. Stifel D: Exploring Alternative Measures of Welfare in the Absence of Expenditure Data Cornell University; 2001.

24. Rossi PH: The Measurement of SES in Health Research: Current Practice and Steps Toward a New Approach. Social Science \& Medicine 2003, 56:769-784.

25. Fu Daniel, Wong Keung, Li Ying Chang, Song Xue He: Rural Migrant Workers in Urban China: Living a Marginalised Life. International Journal of Social Welfare 2007, 16:32-40.

26. Li Lu, Wang Hong-mei, Ye Xue-jun, et al: The Mental Health Status of Chinese Rural-urban Migrant Workers. Soc Psychiatry Psychiatr Epidemiol 2007, 42:716-722.

27. Tan S: Impacts of migration on rural poverty and inequality (in Chinese). Open Times 2009, 10:81-95.

28. Ministry of Finance: Notice on "Financial Management Regulations on The New Cooperative Medical Scheme" (in Chinese) 2008.

29. Zhang LY, Cheng XM, Liu KZ: Balancing the finds in the New Cooperative Medical Scheme in rural China: determinants and influencing factors in two provinces. The International Journal of Health Planning and Management 2010, 25(2):96-118.

30. Bai J: NCMS launched new reimbursement policy, and members will be reimbursed when they are being treated [http://medicine.people.com.cn/GB/ 9563037.html], accessed August 12, 2009.

31. National Bureau of Statistics of China: Report on investigation of Rural-tourban Migrants (in Chinese) 2010.

32. Lin Wanchuan, Liu GGordon, Chen Gang: The Urban Resident Basic Medical Insurance: a Landmark Reform towards Universal Coverage in China. Health Econ 2009, 18:S83-S96.

33. Houweling TAJ, Kunst AE, Mackenbach JP: Measuring health inequality among children in developing countries: does the choice of the indicator of economic status matter? International Journal for Equity in Health 2003, 2:8.

34. McKenzie DJ: Measure Inequality With Asset Indicators. Journal of Population Economics 2005, 18:229-260.

35. Vyas Seema, Kumaranayake Lilani: Constructing Soci-economic Status Indices: How to Use Principal Components Analysis. Health Policy Plan 2006, 21:459-468.

\section{Pre-publication history}

The pre-publication history for this paper can be accessed here: http://www.biomedcentral.com/1471-2458/11/520/prepub

doi:10.1186/1471-2458-11-520

Cite this article as: Qiu et al:: Rural-to-urban migration and its implication for new cooperative medical scheme coverage and utilization in China. BMC Public Health 2011 11:520.

\section{Submit your next manuscript to BioMed Central and take full advantage of:}

- Convenient online submission

- Thorough peer review

- No space constraints or color figure charges

- Immediate publication on acceptance

- Inclusion in PubMed, CAS, Scopus and Google Scholar

- Research which is freely available for redistribution

Submit your manuscript at www.biomedcentral.com/submit
Biomed Central 